\title{
WELFARE POLICY AND MULTI-NATIONAL MONOPOLIES
}

\author{
JOHN RICKARD $^{1}$, ALLEN RUSSELL $^{2}$ and CHRISTINE MARTINI ${ }^{3}$
}

(Received 23 May 1990; revised 19 January 1991)

\begin{abstract}
This paper examines the role of import tariffs and consumption taxes when a product is supplied to a domestic market by a foreign monopoly via a subsidiary. It is assumed that there is no competition in the domestic market from internal suppliers. The home country is able to levy a profits tax on the subsidiary; the objective of our analysis is to determine the levels of tariff or consumption tax which maximise national welfare. Comparisons are made under the two alternative policies from the perspectives of national welfare, total national cost and average national cost. The major policy implication of the analysis is that a consumption tax is the more effective instrument for maximising national welfare provided the profits tax is less than a certain critical value; if the profits tax exceeds this value then a tariff, though in the form of a subsidy, is the most effective instrument. Our results complement, correct and extend an earlier analysis by Katrak (1977) [6].
\end{abstract}

\section{Introduction}

In a very interesting paper, Katrak [6] examined the role of import tariffs and consumption taxes when an importable product is supplied to a domestic market by a foreign monopoly via a subsidiary. It was assumed, primarily, that the home market is served by imports only, so that there is no competition from internal suppliers. The home country is able to levy a profit tax on the subsidiary of the foreign firm. The model, which may be regarded as an extension of optimal tariff theory, also allows for the imposition of tariffs on the imported product or the collection of a consumption tax. A comparison of the respective benefits of an import tariff and consumption tax are

\footnotetext{
${ }^{1}$ Graduate School of Management, Deakin University, Geelong, Victoria 3217.

${ }^{2}$ Department of Mathematics, The University of Melbourne, Parkville, Victoria 3052, Australia.

${ }^{3}$ Department of Accounting and Finance, The University of Melbourne, Parkville, Victoria 3052.

(C) Copyright Australian Mathematical Society 1992, Serial-fee code 0334-2700/92
} 
made by Katrak. An interesting debate on the assumptions and objectives of Katrak's [6] paper appears in De Meza [3] and Katrak's [7] subsequent reply.

Katrak's [6] paper focussed essentially on a closed economy, although some consideration was given to foreign investment by the monopolist's subsidiary. Since then Katrak and others have extended and generalised the earlier analysis to the case of open economies and the operations of multi-national firms. Particular emphasis has been given to the role of export taxes/subsidies in determining whether the associated policies can increase the economic welfare of the host country-see, for example, Katrak [8, 9, 10]. The interested reader is also referred to earlier works by Horst [5], Helleiner [4] and Dasgupta and Stiglitz [2]. In this paper we adopt essentially the same model used by Katrak [6] but present an extended analysis and, we hope, a more meaningful comparison of the welfare benefits and national cost measures of an import tariff and consumption tax. In his analysis, Katrak [6] obtains an optimal tariff rate and also an optimal consumption tax, and then calculates the average costs to the home country under these respective policies. A comparison of these average costs is then made under the assumption that the tariff rate (not necessarily optimal) is equal to the rate of consumption tax, an assumption which Katrak does not justify. In our analysis we also compare the same average costs, but each calculated for their respective optimal tariff rate and optimal consumption tax rate. It is also shown that a comparison of these average costs to the nation is very much dependent upon the profit tax imposed by the home country. We extend the analysis to include a comparison of welfare benefits which again turn out to be directly dependent on the profits tax. Throughout our analysis we assume that the rate of profit tax is constant, as is the situation with company tax in Australia, for example. A more general analysis might allow the tariff, consumption and profit tax rates to be optimised simultaneously.

The model presented is a particular case of imperfect competition in a partial equilibrium setting. In view of the improvements and extensions to Katrak's paper, it is appropriate to adopt the same linear demand and cost functions. Although there exists an extensive literature on imperfect competition in general equilibrium (see O. Hart in [1]), there are difficulties as pointed out by Hart in obtaining specific results when more general functions are employed. In Chapter 3 of [11], Laffont discusses briefly the regulation of a monopoly by means of a tax, again using general demand and cost functions, but the analysis is both brief and elementary, and does not provide nearly so detailed an analysis as given here.

Our results can be summarised as follows: for a country importing a product from a foreign monopolist, we consider the welfare of the home country, and show that whether or not an optimal tariff or optimal consumption tax is 
adopted depends upon the profits tax. Optimal welfare is determined under both tariff and consumption tax, and specifically we show that the maximum level of welfare occurs for a consumption tax provided the profits tax is less than $100 r_{2}^{*} \%$ where $0<r_{2}^{*}<1$. When the profits tax exceeds $100 r_{2}^{*} \%$ the maximum level of welfare occurs under the tariff subsidy. When the profits tax is $100 r_{2}^{*} \%$ the maximum levels of welfare are identical.

It is also of some interest to compare the total and average costs to the country of importing the product. It turns out that for average national costs (per item imported) the preference for tariff or consumption tax policies is qualitatively just the same as that for welfare.

\section{Import tariffs and subsidies}

The following analysis will assume a partial equilibrium setting.

We assume a linear demand function given by

$$
q=\alpha-\beta p,
$$

where $q$ denotes the quantity in demand, $p$ is the price (per unit) to the home consumers, and $\alpha$ and $\beta$ are positive constants. Let $C_{m}$ denote the constant marginal cost, and let the rate of import tariff or subsidy, expressed as a proportion of $C_{m}$, be denoted by $t$; then $t>0$ denotes a tariff, and $t<0$ denotes a subsidy. The corresponding profit function for the importing firm is given by

$$
\begin{aligned}
\pi & =p q-C_{m}(1+t) q \\
& =(\alpha-\beta p)\left(p-C_{m}(1+t)\right),
\end{aligned}
$$

or

$$
\pi=(\alpha-q) q / \beta-C_{m}(1+t) q .
$$

Under profit maximisation, the equilibrium price, $p_{t}$, is given by

$$
p_{t}=\frac{1}{2}\left(\frac{\alpha}{\beta}+C_{m}(1+t)\right),
$$

and the corresponding equilibrium demand, $q_{t}$, is given by

$$
q_{t}=\left(\alpha-\beta C_{m}(1+t)\right) / 2 \text {. }
$$

Note that the second derivative of $\pi$ with respect to either $p$ or $q$ is always negative, so $p_{t}$ and $q_{t}$ do in fact correspond to a maximum profit. Note also that the increase in price due to the tariff is $\frac{1}{2} C_{m} t$, and the corresponding decrease in demand is $\frac{1}{2} \beta C_{m} t$. 
The profit $\pi_{t}$, corresponding to $p_{t}$ and $q_{t}$, is given by

$$
\pi_{t}=\left(\alpha-\beta p_{t}\right)\left(p_{t}-C_{m}(1+t)\right) \text {, }
$$

which after simplification becomes

$$
\begin{aligned}
\pi_{t} & =\beta\left[\frac{\alpha}{\beta}-C_{m}(1+t)\right]^{2} / 4 \\
& =q_{t}^{2} / \beta, \quad \text { using (4). }
\end{aligned}
$$

We now make provision for the imposition of a tax on profits. We assume that the foreign firm has a distribution subsidiary in the home country, and that any profits attributed to this subsidiary are taxable by the home country. We denote the tax rate on profits by $100 r \%$, so that $0 \leq r \leq 1$. The profits tax rate is assumed to be constant, or single level, like the current company tax in Australia, for example. The level at which a profits tax is fixed will presumably be determined by government policy and consideration of taxation in both the domestic and foreign countries. The home country may not wish to discriminate between domestic and foreign firms. If the home country's tax rate is too much higher than that in the foreign country, evasion may occur by means of transfer pricing. Having introduced a tax rate on profits we now investigate costs to the home country, in particular total cost, average cost and marginal cost.

The total cost to the home country is given by the cost of goods purchased by consumers less the revenue from tariff and profit taxes, that is,

$$
T_{t}=\left(p_{t}-C_{m} t\right) q_{t}-r \pi_{t},
$$

which can be written as

$$
T_{t}=\frac{1}{2 \beta} q_{t}\left[\alpha(1-r)+\beta C_{m}(1+r)-\beta C_{m} t(1-r)\right],
$$

using (5). Thus, the average cost to the home country is given by

$$
A_{t}=\frac{1}{2 \beta}\left[\alpha(1-r)+\beta C_{m}(1+r)-\beta C_{m} t(1-r)\right] .
$$

By expressing $t$ in terms of $q_{t}$ from (4), (8) can be written as

$$
A_{t}=C_{m}+\left(\frac{1-r}{\beta}\right) q_{t},
$$

from which we see that the average cost to the home country is made up from the carriage, insurance and freight (c.i.f.) cost $C_{m}$ together with the per unit profit retained by the foreign firm.

To obtain the marginal cost we note that $T_{t}=A_{t} q_{t}$ and hence, from (9) we obtain

$$
T_{t}=q_{t}\left(C_{m}+\left(\frac{1-r}{\beta}\right) q_{t}\right)
$$


from which it readily follows that

$$
M_{t}=\frac{d T_{t}}{d q_{t}}=C_{m}+2\left(\frac{1-r}{\beta}\right) q_{t} .
$$

Bearing in mind that welfare in the home country may be increased by a tariff/subsidy policy, we choose the optimum value of $t$ by maximising the sum of tariff revenue, profit tax revenue and consumer surplus; that is, we calculate $\max _{t} W_{t}$, where

$$
W_{t}=C_{m} t q_{t}+r \pi_{t}+\int_{0}^{q_{t}}\left(p-p_{t}\right) d q
$$

which can be written alternatively as

$$
\max \left(\int_{0}^{q_{t}} p d q-T_{t}\right) .
$$

It now follows readily that (12) leads to the condition

$$
p_{t}=M_{t} \text {. }
$$

Thus, the optimal tariff/subsidy policy is to equate the marginal cost of imports to the marginal utility in home consumption. Using the demand function and (11), (13) is seen to be equivalent to

$$
q_{i}=\frac{\alpha-\beta C_{m}}{3-2 r}
$$

which when combined with (4) can be solved to give the optimal value $t^{*}$ of $t$, namely

$$
t^{*}=\left\{\frac{1-2 r}{3-2 r}\right\}\left\{\frac{\alpha}{\beta C_{m}}-1\right\} .
$$

Thus, optimal tariff/subsidy policy depends explicitly on the rate of taxing profits, being a tariff if profits tax is less than $50 \%$ and a subsidy if profits tax exceeds $50 \%$, provided of course the condition $\alpha>\beta \quad C_{m}$ is satisfied. This condition follows naturally, however, from (14), and will be assumed throughout the subsequent analysis.

\section{Consumption tax}

As in the tariff case we have a linear demand function given by

$$
q=\alpha-\beta(1+c) p
$$

where the consumption tax is $100 c \%$ of the price to the firm, $p$. 
Under profit maximisation, the equilibrium price and demand are given by

$$
p_{c}=\frac{1}{2(1+c)}\left\{\frac{\alpha}{\beta}+C_{m}(1+c)\right\}
$$

and

$$
q_{c}=\frac{1}{2}\left(\alpha-\beta C_{m}(1+c)\right),
$$

respectively, provided of course that $1+c \neq 0$. The condition $1+c \leq 0$ gives rise to an abnormal demand function, and consequently we will assume henceforth that $1+c>0$. It will become apparent later that $1+c=0$ corresponds to a $100 \%$ profit tax, that is, $r=1$. To ensure that $q_{c}$ is nonnegative, we assume that $\alpha \geq \beta C_{m}(1+c)$. This will certainly be satisfied when $\alpha \geq 2 \beta C_{m}$, a condition that we now adopt; notice that this condition includes an earlier condition, namely, $\alpha>\beta C_{m}$.

The change in price due to the consumption tax is therefore $-\frac{\alpha c}{2 \beta(1+c)}, \mathbf{a}$ reduction, while the corresponding decrease in demand is $(1 / 2) \beta c C_{m}$. The corresponding profit can be shown to equal

$$
\pi_{c}=\frac{1}{\beta(1+c)} q_{c}^{2},
$$

which will always be non-negative.

Observe that when $t=c$, we have $p_{c}<p_{t}, q_{c}=q_{t}$, and $\pi_{c}<\pi_{t}$. This means that for a given level of tariff, and the same level of consumption tax, the same quantity of goods will be supplied. However, the tariff produces a higher price to the firm, and also a higher profit. The price to the consumer is the same in each case.

We now turn our attention to the costs incurred by the home country under the consumption tax policy. Using analysis similar to that for the tariff case we obtain, respectively, the total, average and marginal costs given by

$$
\begin{aligned}
T_{c} & =q_{c}\left(C_{m}+\frac{1-r}{\beta(1+c)} q_{c}\right), \\
A_{c} & =C_{m}+\frac{1-r}{\beta(1+c)} q_{c} \\
& =C_{m} \frac{\alpha-(1+r) q_{c}}{\alpha-2 q_{c}},
\end{aligned}
$$

and

$$
\begin{aligned}
M_{c} & =C_{m}\left(1+\frac{2(1-r) q_{c}\left(\alpha-q_{c}\right)}{\left(\alpha-2 q_{c}\right)^{2}}\right) \\
& =C_{m} \frac{\alpha-2 r q_{c}}{\alpha-2 q_{c}} .
\end{aligned}
$$


It follows immediately from (21) that the average cost under the consumption tax takes the same form as for the tariff case, namely the sum of the c.i.f. cost together with the per unit profit retained by the foreign firm. Alternatively, it is readily seen that the average cost is the price (per unit) received by the foreign firm less the profits tax revenue (per unit) received by the home country. Provided $q_{c}<\alpha / 2$, and this is to be expected from (18), both the average and marginal costs exceed $C_{m}$, the c.i.f. cost; and furthermore the marginal cost always exceeds the average cost.

Proceeding as for the tariff case, we now determine the optimal consumption $\operatorname{tax} c^{*}$ by maximizing with respect to $c$,

$$
W_{c}=\int_{0}^{q_{c}}(1+c) p d q-T_{c}
$$

leading to the condition

$$
(1+c) p_{c}=M_{c}
$$

It is easily shown that $(25)$ gives

$$
4 q_{c}^{2}\left(\alpha+\beta C_{m}(c-r)\right)-4 \alpha q_{c}\left(\alpha+\beta C_{m}(c-r)\right)+\alpha^{2}\left(\alpha+\beta C_{m}(c-1)\right)=0,
$$

which, after using (18), leads to the cubic equation

$$
\beta^{2} C_{m}^{2}(1+c)^{3}+\beta C_{m}\left[\alpha-(1+r) \beta C_{m}\right](1+c)^{2}-\alpha^{2}(1-r)=0,
$$

or

$$
u^{3}+(k-1-r) u^{2}-k^{2}(1-r)=0,
$$

where $1+c=u$, and $\alpha /\left(\beta C_{m}\right)=k$. Hence $c^{*}$ can be determined from (27).

It is now interesting to compare the optimal tariff rate and optimal consumption tax rate and see how their relationship depends upon the profits tax rate. We also compare the welfare benefits and the various cost functions under the optimal policies.

\section{A comparison of the two policies}

As pointed out in Katrak [6], if imports are produced in a perfectly competitive foreign industry, and if there is no domestic production competing with the imports, then a consumption tax is equivalent to an import tariff. In the present model, however, the foreign imports come from a monopolist, so it is of interest to examine whether an optimal consumption tax yields the same level of welfare as an optimal tariff.

We now obtain some properties of $c^{*}$ and $t^{*}$, make some comparisons between them, and compare corresponding costs and welfare benefits. 
THEOREM 1. Equation (27) has a unique solution in $[0, \infty)$; that is, the optimum consumption tax $c^{*}$ is unique.

Proof. For given values of $r$ and $k$, let

$$
f(u)=u^{3}+(k-1-r) u^{2}-k^{2}(1-r) .
$$

Since we have assumed that $k \geq 2$, it follows readily that $f(0)<0, f(u) \rightarrow$ $+\infty$ as $u \rightarrow \infty$, and that $f^{\prime}(u) \geq 0$ for $u \geq 0$, meaning that $f(u)$ is an increasing function on $[0, \infty)$. Hence (27) has a unique solution $u^{*}$ in $[0, \infty)$.

It is of considerable interest, and indeed, importance to see how $c^{*}$ and $t^{*}$ behave as functions of the profits tax $r$. In the subsequent analysis it will be convenient and consistent to consider $1+t^{*}$ instead of $t^{*}$. We shall denote $1+t^{*}$ by $v^{*}$, and as before denote $1+c^{*}$ by $u^{*}$. Again, for convenience we shall sometimes use $u$ and $v$ instead of $u^{*}$ and $v^{*}$.

THEOREM 2. The optimal tariff and consumption tax rates have the following properties:

(i) $u^{*} \rightarrow 0$ as $r \rightarrow 1-0$ for all values of $k \geq 2$.

(ii) $u^{*}$ and $v^{*}$ are both decreasing functions of $r$ for any given value of $k \geq 2$.

(iii) $u^{*}=v^{*}$ for only one value $r^{*}$ of $r$ in $[0,1)$ for any given value of $k>2$. If $k=2, u^{*}=v^{*}$ at $r=1$ and also for one value of $r$ in $[0,1)$.

Proof. That (i) is true follows readily from (28).

It follows from (15) that

$$
v^{*}=\frac{2+(1-2 r) k}{3-2 r}
$$

in which case

$$
\frac{d v^{*}}{d r}=\frac{-4(k-1)}{(3-2 r)^{2}}<0,
$$

since $k \geq 2$. To obtain the corresponding result for $u^{*}$, we differentiate (28) with respect to $r$ to give

$$
\frac{d u^{*}}{d r}=\frac{u^{* 2}-k^{2}}{3 u^{* 2}+2 u^{*}(k-1-r)} .
$$

Since it follows from (28) that $0 \leq u^{*}<k, \frac{d u^{*}}{d r}<0$, so $u^{*}$ is also a decreasing function of the profits tax $r$. We now establish (iii). 
It follows from (29) that

$$
r=\frac{k+2-3 v^{*}}{2\left(k-v^{*}\right)}
$$

observing that $v^{*} \neq k$ when $k \geq 2$. Substituting the above expression for $r$ into (28), putting $u^{*}=v^{*}=x$ and simplifying gives

$$
2 x^{3}+(2 k-5) x^{2}-2(k+1) x-k(k-2)=0 .
$$

If $k \geq 2$, this last polynomial equation has only one sign change, and so by Descartes' rule of signs it can have at most one root in $[0, \infty)$; that is, $1+c^{*}$ and $1+t^{*}$, and therefore $c^{*}$ and $t^{*}$ can be equal at most once. We now show that they are equal for exactly one value of $r$ in $[0,1)$.

As observed earlier, $u^{*} \rightarrow 0$ as $r \rightarrow 1$, while from (29) $v^{*} \rightarrow 2-k \leq 0$ as $r \rightarrow 1$, with equality when $k=2$. On the other hand, when $r=0$, $v^{*}=(k+2) / 3$. Substituting $(k+2) / 3$ for $u$ in the left side of (28) (and putting $r=0)$, gives

$$
\frac{(k+2)^{3}}{27}+\frac{(k-1)(k+2)^{2}}{9}-k^{2},
$$

which after simplification becomes $(4 / 27)(k-1)^{3}>0$. Therefore $u^{*}>v^{*}$ at $r=0$, while $\lim _{r \rightarrow 1}\left(u^{*}-v^{*}\right) \leq 0$. F.om this we can conclude that $1+c^{*}$ and $1+t^{*}$ are equal for exactly one value of $r$ in $[0,1)$. Their relationship is depicted in Figures 1(i), (ii) and (iii) (see next page) for $k=2,4$ and 8 respectively.

COROLLARY. There exists $r^{*} \in[0,1]$ such that for $k>2$,

(i) $c^{*}<t, 0 \leq r<r^{*}$;

(ii) $c^{*}=t^{*}, r=r^{*}$;

(iii) $c^{*}>t^{*}, r^{*}<r \leq 1$.

If $k=2$, then $c^{*}=t^{*}$ when $r=1$ and also for one value of $r$ in $[0,1)$.

The results of the corollary now enable us to compare the optimal quantities of goods produced.

THEOREM 3.

$$
\begin{array}{ll}
q_{c}^{*}>q_{t}^{*}, & 0 \leq r<r^{*} ; \\
q_{c}^{*}=q_{t}^{*}, & r=r^{*} ; \\
q_{c}^{*}<q_{t}^{*}, & r^{*}<r \leq 1 .
\end{array}
$$


(i)

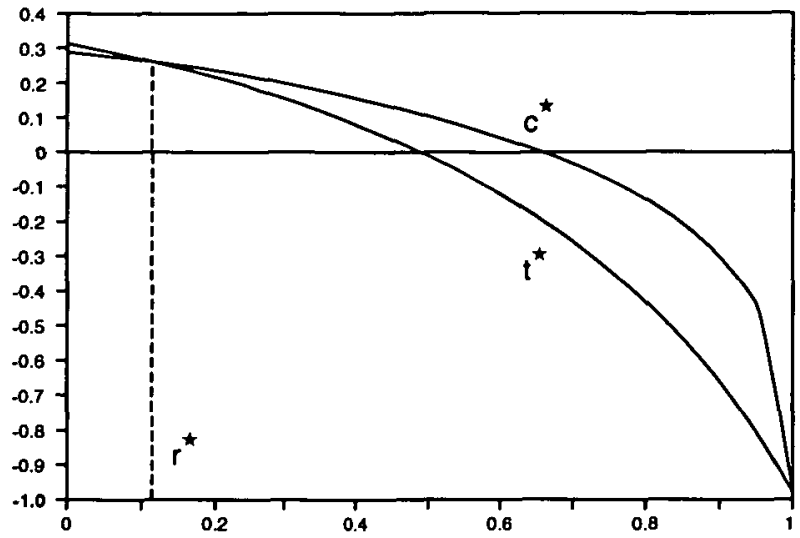

(ii)

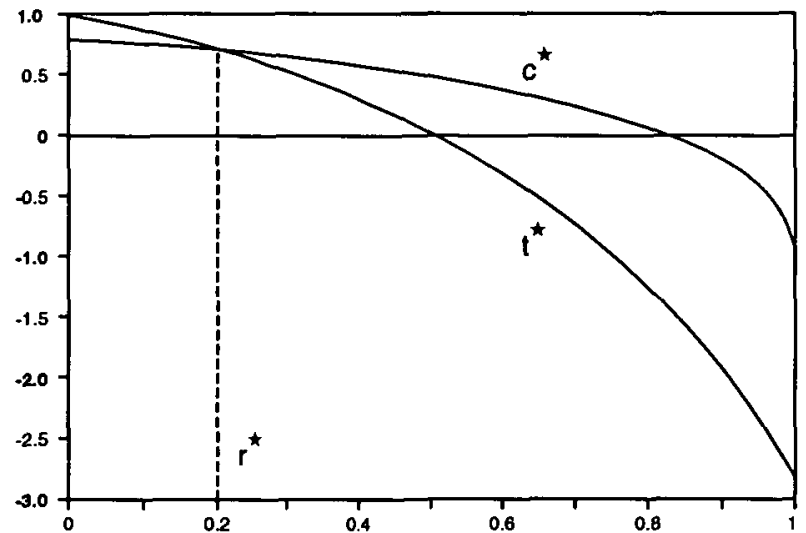

(iii)

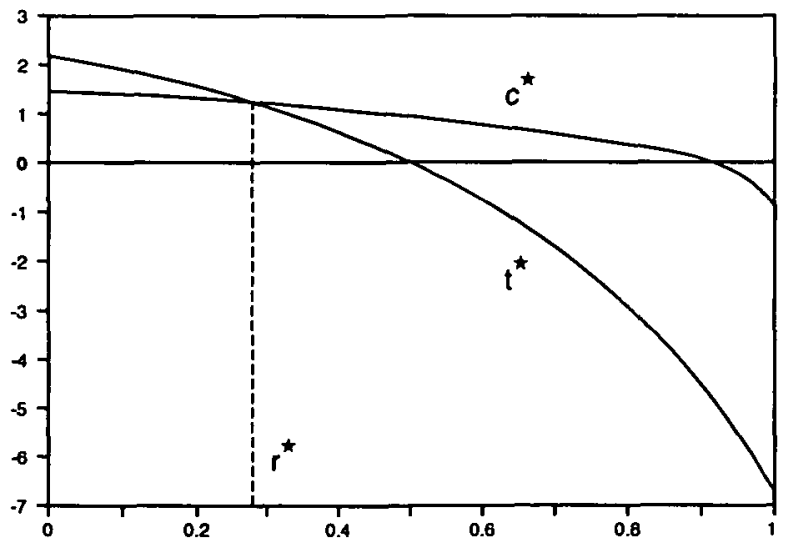

FIgURE 1. Graphs of $c^{*}$ and $t^{*}$ as functions of $r$ for (i) $k=2$, (ii) $k=4$ and (iii) $k=8$. 
Proof. These inequalities follow readily from (4), (18) and Theorem 2, Corollary.

Theorem 4. There exists $r_{1}^{*} \in[0,1]$ such that for $k \geq 2$,

$$
\begin{array}{ll}
A_{t}^{*}>A_{c}^{*}, & 0 \leq r<r_{1}^{*} ; \\
A_{t}^{*}=A_{c}^{*}, & r=r_{1}^{*}, \text { and } r=1 ; \\
A_{t}^{*} \leq A_{c}^{*}, & r_{1}^{*}<r \leq 1 .
\end{array}
$$

Proof. Using (9), (14), (18), (21), and equating $A_{t}^{*}$ and $A_{c}^{*}$ gives

$$
\frac{(1-r)(k-1)}{3-2 r}=\frac{(1-r)\left(k-u^{*}\right)}{2 u^{*}},
$$

where $k=\alpha /\left(\beta C_{m}\right)$. Therefore $r=1$ or

$$
2 u^{*}(k-1)=(3-2 r)\left(k-u^{*}\right) .
$$

Also, from (28),

$$
r=\frac{u^{* 3}+(k-1) u^{* 2}-k^{2}}{u^{* 2}-k^{2}} \text { since } u^{*}<k .
$$

Substituting for $r$ in (31) and simplifying gives

$$
2 u^{* 3}-3 u^{* 2}-2 k(k-1) u^{*}+k^{2}=0,
$$

and this is equivalent to

$$
\left(u^{*}-k\right)\left(2 u^{* 2}+(2 k-3) u^{*}-k\right)=0 .
$$

Since $u^{*}<k, 2 u^{* 2}+(2 k-3) u^{*}-k=0$, and this quadratic equation has only one positive root. Hence $A_{t}^{*}$ and $A_{c}^{*}$ are equal at this root, $r_{1}^{*}$, and at $r=1$. Now at $r=0$,

$$
\begin{aligned}
A_{t}^{*}-A_{c}^{*} & =\frac{\alpha\left(2 u^{*}-3\right)+\beta C_{m} u^{*}}{6 \beta u^{*}} \\
& =\frac{C_{m}}{6 u^{*}}\left[\left(2 u^{*}-3\right) k+u^{*}\right], \quad \text { where } k=\frac{\alpha}{\beta C_{m}} \\
& \geq \frac{C_{m}}{6 u^{*}}\left(5 u^{*}-6\right), \quad \text { since } k \geq 2 \\
& \geq 0 \text { if } u^{*} \geq 6 / 5 .
\end{aligned}
$$


To show that $u^{*} \geq 6 / 5$, let

$$
f(u)=u^{3}+(k-1) u^{2}-k^{2} .
$$

Then $f(0)<0$ and, after simplification,

$$
\begin{aligned}
f\left(\frac{6}{5}\right) & =\frac{-125 k^{2}+180 k+36}{125} \\
& <0 \text { for } k \geq 2 .
\end{aligned}
$$

Hence we must have $u^{*}>6 / 5$, and so at $r=0$ we have shown that $A_{t}^{*} \geq A_{c}^{*}$. The required results now follow. Typical graphs of $A_{t}^{*}$ and $A_{c}^{*}$ are illustrated in Figures 2(i), (ii) and (iii).

Having earlier obtained an optimal tariff rate and optimal consumption tax rate by maximising welfare under the respective policies, we now compare the corresponding welfare benefits.

The optimal value of welfare under a tariff policy is given by

$$
W_{t}^{*}=C_{m} t q_{t}^{*}+\frac{1}{\beta}\left(r+\frac{1}{2}\right)\left(q_{t}^{*}\right)^{2},
$$

which after employing (14) and (15) simplifies to

$$
W_{t}^{*}=\frac{\left(\alpha-\beta C_{m}\right)^{2}}{2 \beta(3-2 r)} \text {. }
$$

Similarly, the optimal value of welfare under a consumption tax is given by

$$
\begin{aligned}
W_{c}^{*}= & \frac{1}{2 \beta}\left(\alpha-\beta C_{m}\right)\left(\alpha-\beta C_{m} u^{*}\right)-\frac{1}{4 \beta}\left(\frac{1}{2}+\frac{1-r}{u^{*}}\right)\left(\alpha-\beta C_{m} u^{*}\right)^{2} \\
= & \frac{1}{2 \beta}\left(\alpha-\beta C_{m}\right)\left(\alpha-\beta C_{m} u^{*}\right)-\frac{1}{8 \beta u^{*}}\left(u^{*}+2\right)\left(\alpha-\beta C_{m} u^{*}\right)^{2} \\
& +\frac{r}{4 \beta u^{*}}\left(\alpha-\beta C_{m} u^{*}\right)^{2} .
\end{aligned}
$$

Putting $W_{t}^{*}=W_{c}^{*}=W$, and substituting for $r$ from (33) we obtain

$$
\begin{aligned}
W= & \frac{1}{2 \beta}\left(\alpha-\beta C_{m}\right)\left(\alpha-\beta C_{m} u^{*}\right)-\frac{1}{8 \beta u^{*}}\left(u^{*}+2\right)\left(\alpha-\beta C_{m} u^{*}\right)^{2} \\
& +\frac{1}{8 \beta u^{*}}\left(3-\frac{\left(\alpha-\beta C_{m}\right)^{2}}{2 \beta W}\right)\left(\alpha-\beta C_{m} u^{*}\right)^{2}
\end{aligned}
$$




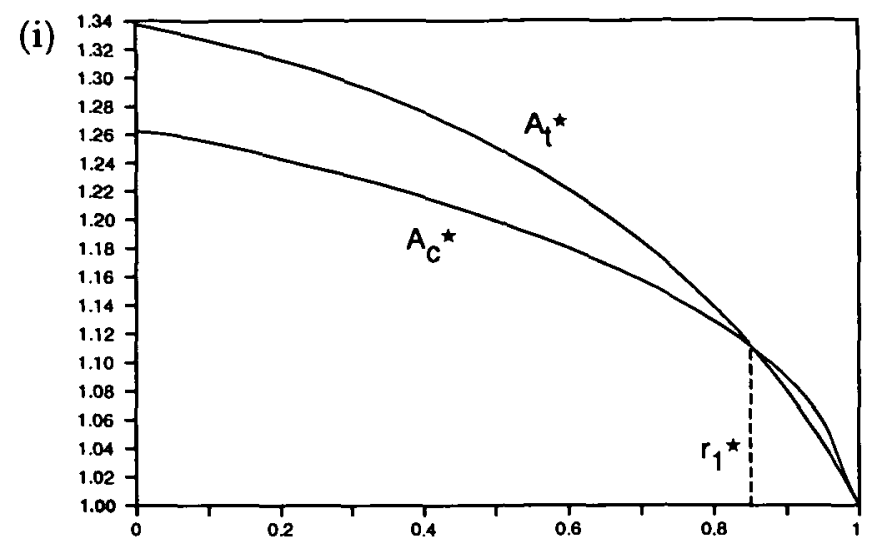

(ii)

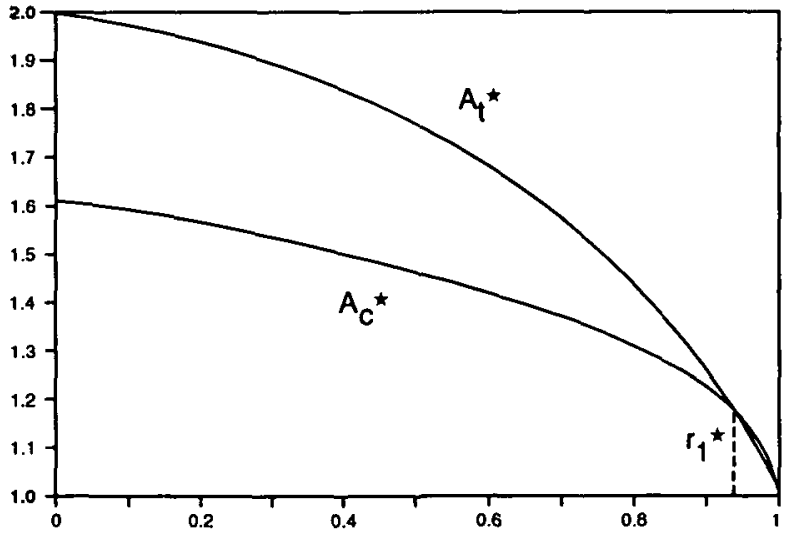

(iii)

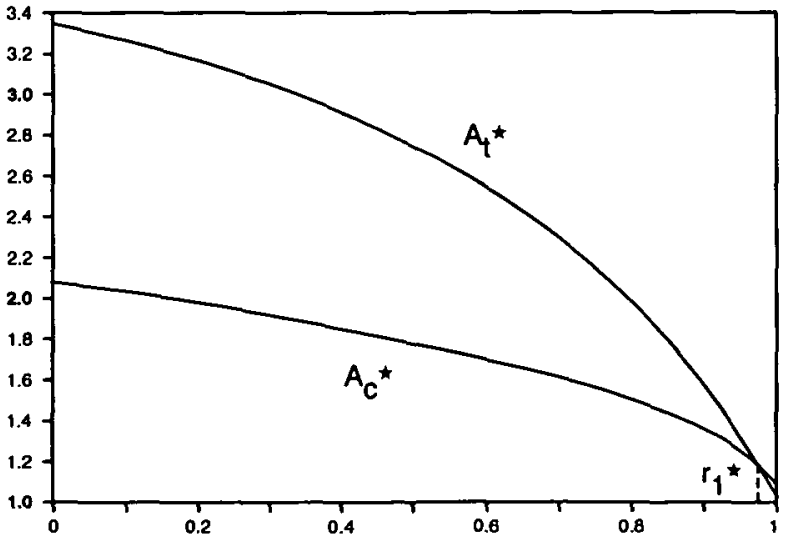

FIGURE 2. Graphs of $A_{c}^{*}$ and $A_{t}^{*}$ as functions of $r$ for (i) $k=2$, (ii) $k=4$ and (iii) $k=8$. 
which on re-arranging can be written as

$$
\begin{gathered}
16 \beta^{2} u^{*} W^{2}-2 \beta W\left(\alpha-\beta C_{m} u^{*}\right)\left[\beta C_{m} u^{* 2}+\left(3 \alpha-5 \beta C_{m}\right) u^{*}+\alpha\right] \\
+\left(\alpha-\beta C_{m}\right)^{2}\left(\alpha-\beta C_{m} u^{*}\right)^{2}=0
\end{gathered}
$$

It is clear that (35) has at most two real roots.

We now analyse the behaviour of $W_{t}^{*}$ and $W_{c}^{*}$ at $r=0$ and as $r \rightarrow 1$.

ThEOREM 5. When $r=0, W_{c}^{*}>W_{t}^{*}$ and $\lim _{r \rightarrow 1} W_{t}^{*} \geq \lim _{r \rightarrow 1} W_{c}^{*}$.

Proof. The optimal consumption tax rate $c^{*}$ is determined from the equation

$$
u^{3}+(k-1-r) u^{2}-k^{2}(1-r)=0 .
$$

If we put $u=(1-r) y$, then (36) becomes

$$
(1-r) y^{3}+(k-1-r) y^{2}=k^{2} /(1-r),
$$

and it is clear from this equation that as $r \rightarrow 1$ from below, $y$ cannot tend to a finite limit; so $y \rightarrow \infty$ as $r \rightarrow 1$. Therefore $(1-r) / u \rightarrow 0$ as $r \rightarrow 1$. It also follows readily from (36) that $u \rightarrow 0$ as $r \rightarrow 1$. Therefore, from (18), $q_{c}^{*} \rightarrow \frac{1}{2} \alpha$ as $r \rightarrow 1$. Then

$$
\begin{aligned}
W_{c}^{*}= & \frac{1}{\beta}\left(\alpha-\beta C_{m}\right) q_{c}^{*}-\frac{1}{\beta}\left(\frac{1}{2}+\frac{1-r}{u^{*}}\right)\left(q_{c}^{*}\right)^{2} \\
& \rightarrow \frac{\alpha\left(3 \alpha-4 \beta C_{m}\right)}{8 \beta} \text { as } r \rightarrow 1 .
\end{aligned}
$$

Similarly it can be shown that

$$
W_{t}^{*} \rightarrow \frac{\left(\alpha-\beta C_{m}\right)^{2}}{2 \beta} \text { as } r \rightarrow 1 .
$$

Therefore, after simplification,

$$
\lim _{r \rightarrow 1}\left(W_{t}^{*}-W_{c}^{*}\right)=\frac{\left(\alpha-2 \beta C_{m}\right)^{2}}{8 \beta} \geq 0
$$

At $r=0,(36)$ becomes

$$
u^{3}+(k-1) u^{2}-k^{2}=0
$$

and

$$
\begin{aligned}
W_{c}^{*}-W_{t}^{*}= & \frac{1}{2 \beta}\left(\alpha-\beta C_{m}\right)\left(\alpha-\beta C_{m} u^{*}\right)-\frac{u^{*}+2}{8 \beta u^{*}}\left(\alpha-\beta C_{m} u^{*}\right)^{2} \\
& -\frac{\left(\alpha-\beta C_{m}\right)^{2}}{6 \beta} .
\end{aligned}
$$


Putting $k=\alpha /\left(\beta C_{m}\right)$, the last equation can be written

$$
\begin{aligned}
\frac{W_{c}^{*}-W_{t}^{*}}{\beta^{2} C_{m}^{2}} & =\frac{(k-1)\left(k-u^{*}\right)}{2 \beta}-\frac{\left(u^{*}+2\right)\left(k-u^{*}\right)^{2}}{8 \beta u^{*}}-\frac{(k-1)^{2}}{6 \beta} \\
& =\frac{12 u^{*}(k-1)\left(k-u^{*}\right)-3\left(u^{*}+2\right)\left(k-u^{*}\right)^{2}-4 u^{*}(k-1)^{2}}{24 \beta u^{*}} .
\end{aligned}
$$

The numerator of the last expression can be written, after using (37), in the form

$$
u^{*}\left(5 k+3 u^{*}-2\right)\left(k+2-3 u^{*}\right),
$$

and this will be non-negative if $u^{*} \leq(1 / 3)(k+2)$. To show this let $f(u)=$ $u^{3}+(k-1) u^{2}-k^{2}$. Then $f(0)<0$, and $f\left(\frac{k+2}{3}\right)$ after simplification becomes $(4 / 27)(k-1)^{3}>0$.

Hence $u^{*}$ lies between 0 and $(1 / 3)(k+2)$, so $u^{*}<(1 / 3)(k+2)$.

Hence $W_{c}^{*}>W_{t}^{*}$ when $r=0$. Finally, we can compare $W_{c}^{*}$ and $W_{t}^{*}$.

THEOREM 6. There exist $r_{2}^{*} \in[0,1]$ such that

$$
\begin{array}{ll}
W_{c}^{*}>W_{t}^{*}, & 0 \leq r<r_{2}^{*} ; \\
W_{c}^{*}=W_{t}^{*}, & r=r_{2}^{*} ; \\
W_{c}^{*}<W_{t}^{*}, & r_{2}^{*}<r \leq 1 .
\end{array}
$$

Proof. These results follow from Theorem 5 and (35).

Typical relationships between $W_{c}^{*}$ and $W_{t}^{*}$ are depicted graphically in Figures 3(i), (ii) and (iii) (see next page).

The following result exhibits the relative order of the various critical rates of profits tax.

TheOREM 7. If, as before, $k=\alpha / \beta C_{m}$, then $r^{*}<\frac{1}{2}<r_{2}^{*}<\frac{k}{k+1}<r_{1}^{*}$.

Proof. First of all, it follows readily from (15) and (27) that $t^{*}$ and $c^{*}$ are zero when $r=1 / 2$ and $k /(k+1)$ respectively. When $r=1 / 2$ it follows from (32) and (33) that $W_{t}^{*}=\frac{\left(\alpha-\beta C_{m}\right)^{2}}{4 \beta}$ and

$$
W_{c}^{*}=\frac{\left(\alpha-\beta C_{m}\right)\left(\alpha-\beta C_{m} u^{*}\right)}{2 \beta}+\frac{\left(\alpha-\beta C_{m} u^{*}\right)^{2}\left(1+u^{*}\right)}{8 \beta u^{*}} .
$$

Hence, putting $k=\alpha / \beta C_{m}$, it is clear that the sign of $W_{c}^{*}-W_{t}^{*}$ is the sign 
(i)

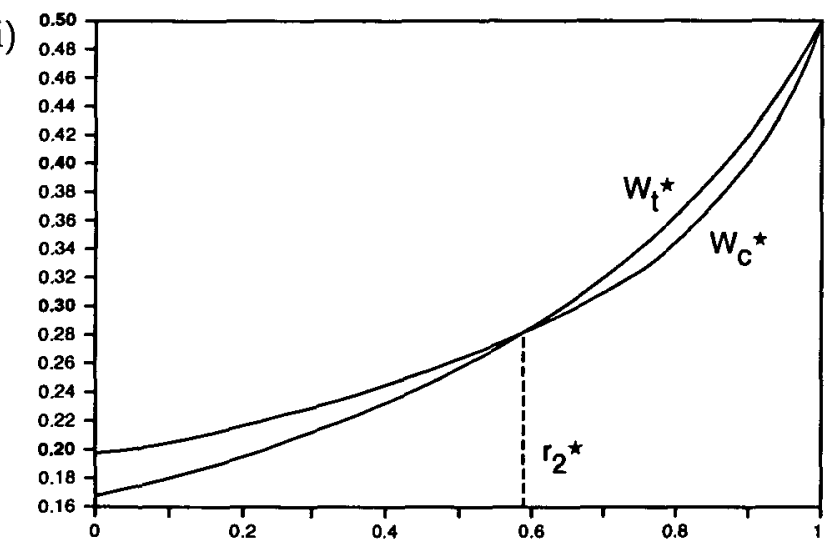

(ii)

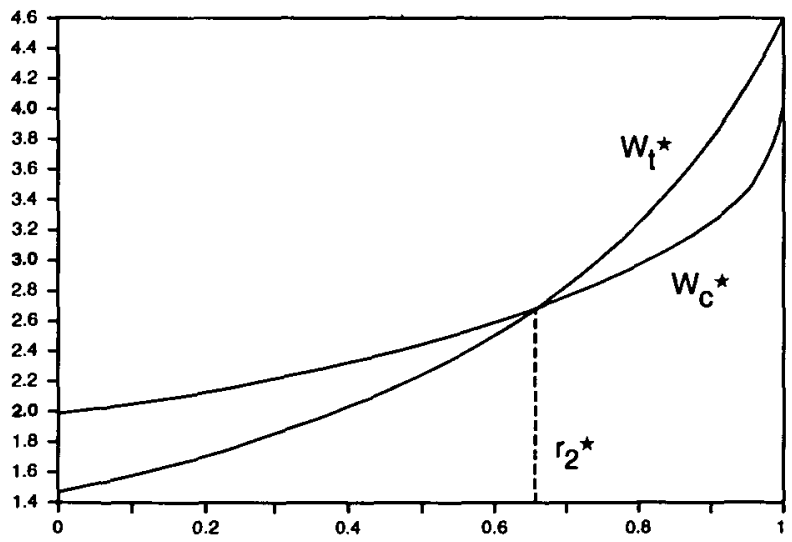

(iii)

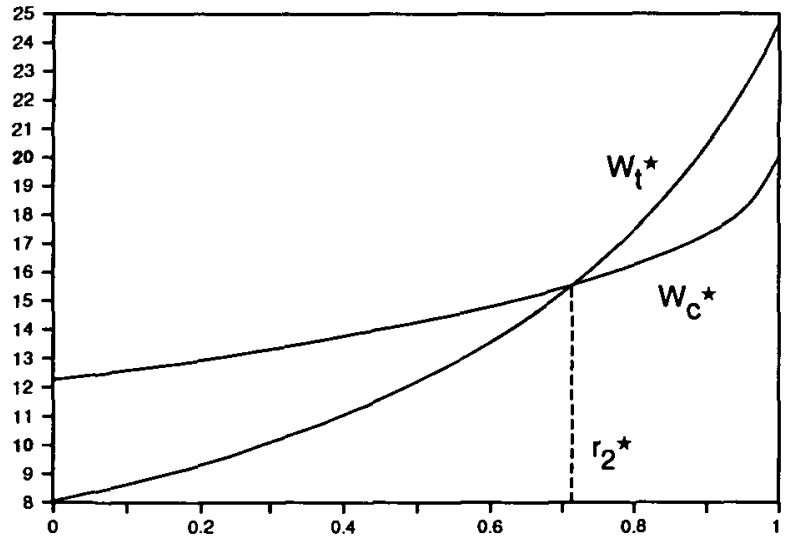

FIGURE 3. Graphs of $W_{c}^{*}$ and $W_{t}^{*}$ as functions of $r$ for (i) $k=2$, (ii) $k=4$ and (iii) $k=8$. 
of

$$
\begin{array}{r}
(k-1)\left(k-u^{*}\right)+\frac{\left(k-u^{*}\right)^{2}\left(1+u^{*}\right)}{4 u^{*}}-\frac{(k-1)^{2}}{2} \\
=\frac{(k-1)\left(k+1-2 u^{*}\right)}{2}+\frac{\left(k-u^{*}\right)^{2}\left(1+u^{*}\right)}{4 u^{*}} .
\end{array}
$$

Now, let $f(u)=u^{3}+(k-1-r) u^{2}-k^{2}(1-r)$ with $r=1 / 2$, so that $f(u)=u^{3}+(k-3 / 2) u^{2}-k^{2} / 2$. Then $f(0)<0$, and

$$
f\left(\frac{k+1}{2}\right)=\frac{(k+1)^{3}}{8}+\left(k-\frac{3}{2}\right) \frac{(k+1)^{2}}{4}-\frac{1}{2} k^{2}
$$

which is readily shown to be positive. Consequently $u^{*}<(k+1) / 2$, and it follows from (39) that $W_{c}^{*}>W_{t}^{*}$. It therefore follows from Theorem 6 that $r_{2}^{*}>1 / 2$. We now turn our attention to average costs and show that $r_{1}^{*}>k /(k+1)$. When $r=k /(k+1), u^{*}=1$ and

$$
\begin{aligned}
A_{t}^{*}-A_{c}^{*} & =\frac{1}{k+1}\left(\frac{k-1}{3-2 r}-\frac{k-1}{2}\right) \\
& =\frac{1}{k+1}\left[\frac{(k-1)(k+1)}{k+3}-\frac{k-1}{2}\right] \\
& =\frac{(k-1)^{2}}{2(k+1)(k+3)}>0 .
\end{aligned}
$$

It therefore follows from Theorem 4 that $r_{1}^{*}>k /(k+1)$. Again, when $r=k /(k+1), u^{*}=1$, so, using (32) and (33), the sign of $W_{t}^{*}-W_{c}^{*}$ is the sign of

$$
\frac{(k-1)^{2}(k+1)}{k+3}-(k-1)^{2}+\frac{3}{4}(k-1)^{2}+\frac{k(k-1)^{2}}{2(k+1)},
$$

and this simplifies to

$$
\frac{(k-1)^{4}}{4(k+1)(k+3)}>0 \text {. }
$$

Hence $W_{t}^{*}>W_{c}^{*}$ when $r=k /(k+1)$, and so it follows from Theorem 6 that $r_{2}^{*}<k /(k+1)$. Finally when $r=1 / 2$, it follows from (28) that $u^{3}+(k-3 / 2) u^{2}-k^{2} / 2=0$, and from (15) that $t^{*}=0$. If $f(u)=u^{3}+$ $(k-3 / 2) u^{2}-k^{2} / 2$ then $f(1)=k-1 / 2-k^{2} / 2<0$.

Therefore $u^{*}>1$, so $c^{*}>0=t^{*}$, and hence it follows from Theorem 2 Corollary that $r^{*}<1 / 2$, as required. 


\section{Discussion}

It is shown in Theorem 6 that $W_{c^{*}}>W_{t^{*}}$ for $0 \leq r<r_{2}^{*}, W_{c^{*}}=W_{t^{*}}$ for $r=r_{2}^{*}$, and $W_{c^{*}}<W_{t^{*}}$ for $r_{2}^{*}<r \leq 1$. Thus for a profits tax less than $r_{2}^{*}$, welfare benefits under a consumption tax are superior to those under a tariff. This situation is reversed if the profits tax exceeds $r_{2}^{*}$, so that optimal welfare occurs under a tariff policy, but in this case it follows from Theorem 7 that the tariff is in fact a subsidy. It is important to note that optimal welfare is never attained under the application of a tariff tax; whenever a tariff policy prevails it is in the form of a subsidy.

Katrak compares the two policies by considering average costs for an import tariff and for a consumption tax. However, he does so by equating the tariff rate and the consumption tax rate, that is by putting $t=c$, and then showing that the average cost under an import tariff exceeds the average cost under a consumption tax. Putting $t=c$ is tantamount to requiring the same level of supplies under the two policies, a requirement which is not immediately apparent. If we adopt this criterion in our approach we obtain the same result as Katrak. However, if average costs are to be employed as a means of comparison, then a more meaningful procedure would be to compare average costs evaluated at their respective optimal rates, that is compare $A_{t^{*}}$ and $A_{c^{*}}$.

The analysis necessary for this comparison is contained in Theorem 4. It is shown there that $A_{t^{*}}>A_{c^{*}}$ for $0 \leq r<r_{1}^{*}, A_{t^{*}}=A_{c^{*}}$ for $r=r_{1}^{*}$, and $A_{t^{*}}<A_{c^{*}}$ for $r_{1}^{*}<r \leq 1$. Thus for a profits tax less than $r_{1}^{*}$, we find that the average cost for an optimal tariff exceeds that for an optimal consumption tax, but for a profits tax exceeding $r_{1}^{*}$, the trend is reversed. The lack of dependence of Katrak's results on the profits tax is a direct result of not considering optimal tariff and consumption tax rates.

Perhaps a more meaningful comparison of costs to the nation under the respective policies could be gained by consideration of total costs rather than average costs. A detailed analysis of total costs will not be included here, but we note, in passing, that in the particular cases depicted in Figures 4(i), (ii) and (iii) the total cost to the nation is greatest under a tariff policy irrespective of the profits tax. 
(i)

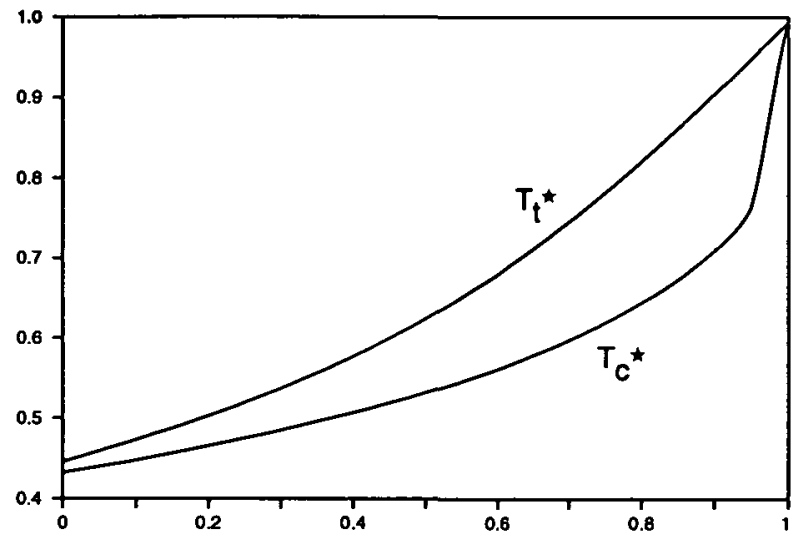

(ii)

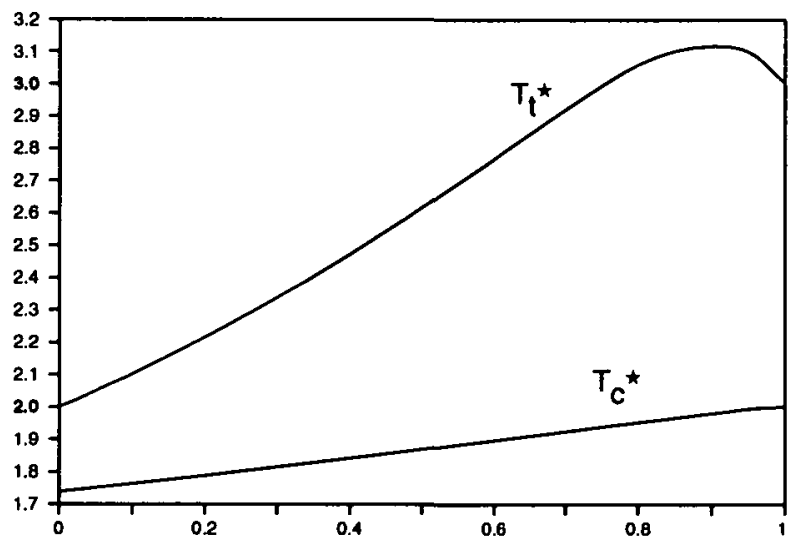

(iii)

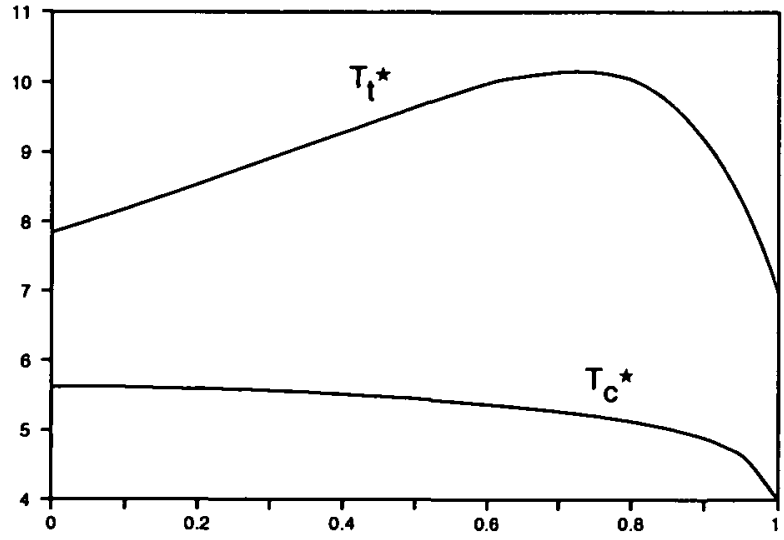

Figure 4. Graphs of $T_{c}^{*}$ and $T_{l}^{*}$ as functions of $r$ for (i) $k=2$, (ii) $k=4$ and (iii) $k=8$ 


\section{Acknowledgements}

The authors wish to acknowledge useful discussions with Victor Kacala, Peter Lloyd and Philip Williams.

\section{References}

[1] K. J. Arrow and S. Honkapohja (Ed.), Frontiers of economics, (Basil Blackwell, 1985).

[2] P. Dasgupta and J. E. Stiglitz, "Benefit-cost analysis and trade policies", Journal of Political Economy, 82 (1984) 1-33.

[3] D. De Meza, "Commercial policy towards multinational monopolies-reservations on Katrak", Oxford Economic Papers, 31 (1979) 334-337.

[4] G. K. Helleiner, "Manufactured exports from less developed countries and multinational firms", Economic Journal, 83 (1973) 21-47.

[5] T. Horst, "The theory of the multinational firm: optimal behaviour under different tariff and tax rates", Journal of Political Economy, 79 (1971) 1059-1072.

[6] H. Katrak, "Multinational monopolies and commercial policy", Oxford Economic Papers, 29 (1977) 283-291.

[7] H. Katrak, "Multinational monopolies and commercial policy: A qualification and reply", Oxford Economic Papers, 31 (1979) 508-511.

[8] H. Katrak, "Multinational monopolies and monopoly regulation", Oxford Economic Papers, 32 (1980) 451-466.

[9] H. Katrak, "Multinational firms' global strategies: host country indigenisation of ownership and welfare", Journal of Development Economics, 13 (1983) 331-348.

[10] H. Katrak, "Pricing policies of multinational enterprises: host country regulation and welfare", Journal of International Economics, 16 (1984) 327-340.

[11] J. J. Laffont, Fundamentals of Public Economics, (MIT Press, 1988). 